\title{
Laser Treatment of Pediatric Vascular Lesions
}

\author{
Patrick D. Cole, M.D., ${ }^{1}$ Michael L. Sonabend, M.D., ${ }^{2}$ and Moise L. Levy, M.D. ${ }^{3}$
}

Since its introduction in 1967, laser therapy has benefited patients and physicians alike. After the first clinical application by Goldman (Anderson RR, Parrish JA. Science 1983;220:524-527), laser therapy has become indispensable in the management of vascular birthmarks. In selecting a proper balance of wavelength, pulse duration, and energy density (fluence), the physician can mold laser energy to effectively manage lesions once considered untreatable. Now, the vast array of lesions amenable to laser therapy continues to expand. By advancing our understanding of both laser technology and vascular lesion biology, the goal of providing optimal clearance with minimal morbidity moves ever closer.

KEYWORDS: Laser therapy, vascular lesions, fluence, pulse duration, wavelength, energy density

$\mathrm{B}_{\mathrm{y}}$ providing a revolutionary solution to difficult clinical problems, the introduction of laser therapy has transformed both dermatology and plastic surgery. Quickly replacing radiation, excision, cryosurgery, or camouflage, laser thermocoagulation of vascular lesions is now regularly employed in both dermatology and plastic surgery. Although early ruby and argon ion lasers were effective for a variety of vascular lesions, nonspecific thermal damage, frequent scarring, and tissue atrophy greatly limited clinical application. ${ }^{1,2}$ The later introduction of yellow-light systems provided enhanced vascular selectivity, reduced melanin absorption, and minimized scarring. During the 1980s, the introduction of millisecond-pulsed, flashlamp dye lasers ${ }^{1-3}$ further optimized selective photocoagulation while minimizing collateral damage. Although alternatives, such as the potassium titanyl phosphate (KTP), red/infrared (IR), or intense pulsed light lasers, are available, pulsed dye lasers continue to be the standard of care for a majority of pediatric vascular lesions. ${ }^{1-5}$ After a 40 -year evolution, laser therapy has assumed an ever-expanding role in dermatology and plastic surgery due to excellent precision and an exemplary safety record.

\section{ELEMENTS OF LASER THERAPY}

In 1983, Anderson and Parrish ${ }^{1}$ introduced the theory of selective photothermolysis: laser energy can be specifically deposited within a target tissue (a chromophore) resulting in controlled, thermal injury with minimal collateral destruction. Because energy penetration into the skin relies on a balance of absorption and energy scattering, optimal therapy depends on the proper selection of basic laser elements: (1) wavelength, (2) pulse duration, (3) energy density (fuence), (4) spot size, and (5) an epidermal cooling system. By manipulation of these parameters, laser therapy can be tailored for specific cutaneous applications to create maximum target tissue destruction with minimal injury to neighboring tissue. $^{1-5}$
${ }^{1}$ Division of Plastic Surgery, ${ }^{2}$ Department of Dermatology, Baylor College of Medicine, Houston, Texas; ${ }^{3}$ Dermatology Services and Birthmark Center, Texas Children's Hospital, Houston, Texas.

Address for correspondence and reprint requests: Patrick D. Cole, M.D., Division of Plastic Surgery, Baylor College of Medicine, 1709 Dryden, Suite 1600, BCM Mail Stop: 340, Houston, TX 77030.
Lasers in Plastic Surgery; Guest Editor, Ramsey F. Markus, M.D. Semin Plast Surg 2007;21:159-166. Copyright (C) 2007 by Thieme Medical Publishers, Inc., 333 Seventh Avenue, New York, NY 10001, USA. Tel: +1(212) 584-4662.

DOI 10.1055/s-2007-991184. ISSN 1535-2188. 


\section{Wavelength}

Wavelength must be selected according to the absorption pattern of the intended target. In vascular lesions, the chromophore is typically oxyhemoglobin. Appropriate heating of intravascular oxyhemoglobin results in coagulation and surrounding vessel destruction. Wavelength also affects dermal penetration depth: with longer wavelengths $(<1200 \mathrm{~nm})$, laser energy is available to deeper tissues. ${ }^{1-4}$ Whereas vascular lesions were initially treated at $577 \mathrm{~nm}$, newer yellow-light systems make use of the 585- to 600-nm wavelengths. Because melanin absorption inversely decreases with increasing wavelength, the use of longer wavelengths during treatment of darker-skinned patients offers a potential advantage of decreased dyspigmentation. Whereas extended wavelength lasers and intense pulsed light systems have been developed for increased dermal penetration, the pulsed dye laser remains the standard treatment for congenital vascular lesions. ${ }^{3-7}$

\section{Pulse Duration}

The pulse duration, or tissue exposure time, must allow for adequate heating of the target to ensure irreversible injury yet prevent unwanted damage to neighboring tissue. Defined as the time interval required for target cooling to one half of its maximum temperature during irradiation, the chromophore's thermal relaxation time must be greater than or equal to a selected pulse duration for effective therapy. ${ }^{6-9}$ Because a vessel's thermal relaxation time is proportional to the square of its diameter, larger vasculature is often resistant to moderate intervals of exposure. Excessive pulse durations allow heat to dissipate into surrounding structures, which may result in scarring, permanent dyspigmentation, and poor photothermocoagulation. ${ }^{6-9}$ Because vessel size within vascular lesions varies widely, no single pulse duration may be universally optimal for all lesions; however, pulse durations of 1 to 13 milliseconds appear to be most effective for capillary malformations/port wine stain (PWS). ${ }^{10-13}$

\section{Energy Density}

The energy density, or fluence $\left(\mathrm{J} / \mathrm{cm}^{2}\right)$, of the laser must be sufficient to heat target tissue to $\sim 70^{\circ} \mathrm{C}$ to irreversibly injure target tissue within the allotted pulse duration interval. ${ }^{1-5}$ In large vessels, poor thermal deposit due to reduced energy absorption by larger blood volumes must be compensated for by increasing fluence. Conversely, very small vessels containing few erythrocytes to collect thermal energy often fail to sustain appropriate damage; higher fluence is required in this instance as well. ${ }^{1-5}$ Because vessel diameter within vascular lesions varies significantly, no single fluence setting is universally promoted for a particular lesion. Instead, energy density should be selected according to the individual purpuric threshold of each lesion. ${ }^{3-7}$

\section{Spot Size}

The desired spot size, or laser light diameter, can be targeted by observing the immediate wheal-and-flare response after laser discharge. ${ }^{4-9}$ Increased beam diameters allow greater tissue penetration, more uniform energy transmission, and more rapid treatment. As a result of deeper penetration, increased beam diameters better translate energy into vascular injury to effectively destroy larger and deeper vascular structures. Per unit of radiant energy expended, large spot sizes also produce increased volumetric heat production with improved efficiency. ${ }^{4-9}$ To avoid losing specificity, though, the spot size used should not be larger than the target lesion. Although more common spot sizes range from 7 to $10 \mathrm{~mm}$, recent market entries utilize larger beams with diameter from 10 to $12 \mathrm{~mm} .{ }^{10-15}$ Although large spot sizes offer some advantages, the maximum fluence achieved from a power source decreases with increasing spot size and may limit the use very large spot sizes only to situations where a low fluence is acceptable. ${ }^{5-9}$

\section{Epidermal Cooling}

Cooling techniques allow the application of increased fluency while minimizing unwanted epidermal injury. In cooling the epidermis, higher levels of radiant energy are tolerated, discomfort is minimized, and therapeutic outcome is improved. Whereas early techniques included ice-cube application, cold gels, or aluminum rollers, ${ }^{1-9}$ more contemporary methods of direct epidermal cooling utilize continuously cooled plates of conductive material, such as glass or sapphire. ${ }^{4,7}$ Chilled-air application is also one of the latest advances in epidermal cooling. ${ }^{11-16}$ During treatment, late-generation cooling devices deliver pulsed cryogen chilled between $-4^{\circ} \mathrm{C}$ to $-32^{\circ} \mathrm{C}$. ${ }^{9,11}$ Current coolant settings vary from 30 - to 50 -millisecond durations with 30 - to 50-millisecond delay before the onset of the laser pulse. ${ }^{11-14}$ Such cooling prevents heat from dissipating into the epidermis and therefore decreases complications.

\section{DEVICES IN CURRENT LASER THERAPY}

\section{Pulsed Dye Laser}

Recently, a variety of lasers have been developed for the treatment of vascular lesions. Foremost among these in usage is the pulsed dye laser (PDL). Containing rhodamine dye, vascular PDL light emission may be stimulated by a xenon flashlamp to produce light at 585 to $600 \mathrm{~nm}$ in short ( 0.45 millisecond), long ( 1.5 milliseconds) and very long pulses (1.5 to 40 milliseconds). ${ }^{6-9}$ Although 
A
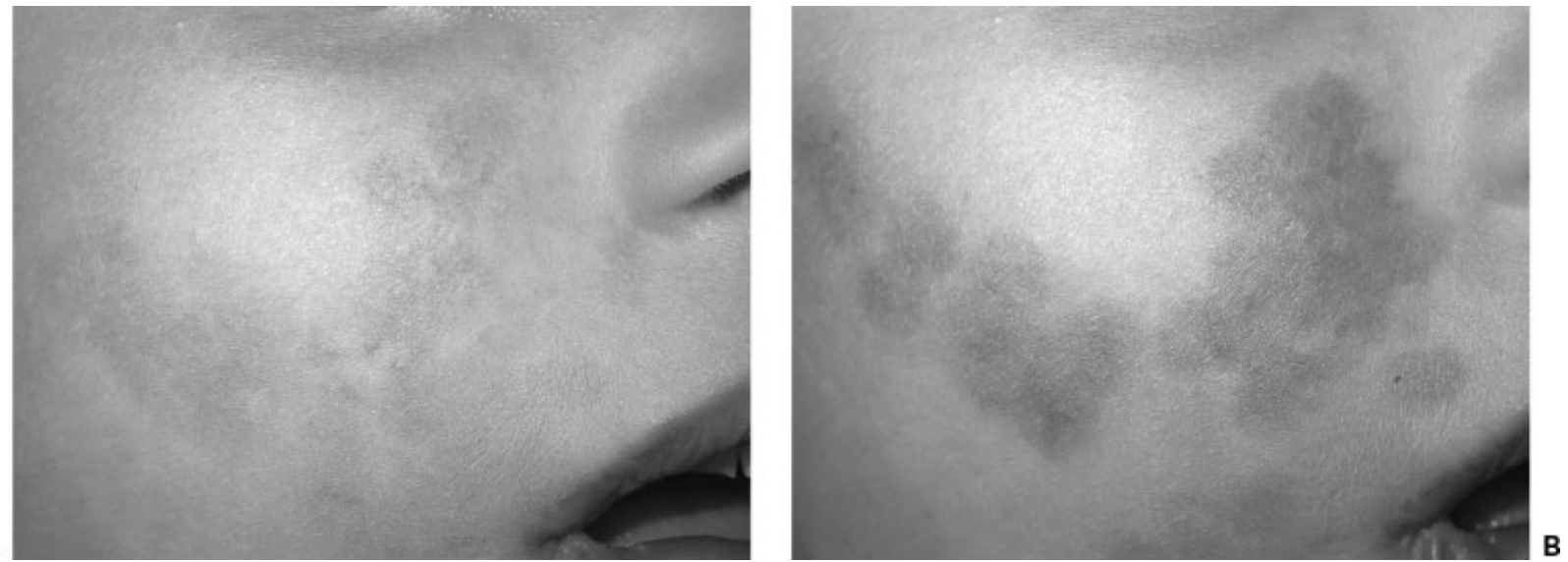

Figure 1 (A) Photograph of a child with facial CM after one treatment with PDL. (B) Posttreatment photograph (PDL, $595 \mathrm{~nm}$, 1.5 milliseconds).

initially recommended for use in pale-skinned patients, recent reports demonstrate excellent results on an array of darker skin tones. ${ }^{14-17}$ The recent addition of dynamic cooling devices has further reduced epidermal disruption, dyspigmentation, scarring, and patient discomfort. ${ }^{411} \mathrm{At}$ 595-nm wavelength, a 1.5-millisecond pulse-width, and energy fluences of 11 to $12 \mathrm{~J} / \mathrm{cm}^{2}$ with dynamic cooling spray, Geronemus ${ }^{6}$ used the pulsed dye Sclerolaser (Candela Corp., Wayland, MA) to clear greater than $75 \%$ of PWS lesions. The 595-nm wavelength can penetrate deeper into the skin than earlier PDLs with shorter wavelengths such as 577 or $585 \mathrm{~nm}$; thus, deeper vessels are more effectively targeted. ${ }^{14,17,18}$ A longer pulse duration is more appropriate for large-caliber vasculature and offers improved efficacy over shorter pulse-width for such lesions. For smaller vessels, short pulse durations are most effective, but longer pulse-widths can also yield results while minimizing bruising. ${ }^{16-19}$ (Figs. 1 and 2) With the addition of epidermal cooling, higher energy fluences may be utilized with enhanced epidermal protection. Clinically, this translates into optimal lesion clearance coupled with minimal epidermal dyspigmentation. Whereas ear- lier attempts used ice cubes, chilled water, and ice gels, contemporary cooling methods use liquid cryogen sprays $^{14-19}$ and cold-air cooling ${ }^{13-19}$ in laser therapy.

\section{KTP Lasers}

A variety of pulsed KTP lasers has recently been introduced for the treatment of vascular lesions. The KTP crystals are reliable, convenient to work with, and readily available. Whereas the mechanisms of these devices vary, each produces millisecond-domain pulses at $532 \mathrm{~nm}^{20}$ Treatment of lesions containing larger vessels has been promising using larger spot sizes ( 3 to $5 \mathrm{~mm}$ ) and pulse duration of 10 to 50 milliseconds in duration at fluences of 14 to $20 \mathrm{~J} / \mathrm{cm}^{2} .^{20,21}$ Cooling also appears to provide a significant benefit in protecting the epidermis, thus allowing use of higher, more effective fluences. Disadvantages of the 532-nm light source is that although blood-selective absorption is equal to $585 \mathrm{~nm}$, it penetrates less deeply and is, therefore, less effective for deeper targets. ${ }^{20,21}$ Furthermore, melanin absorption is increased with shorter wavelengths, making this
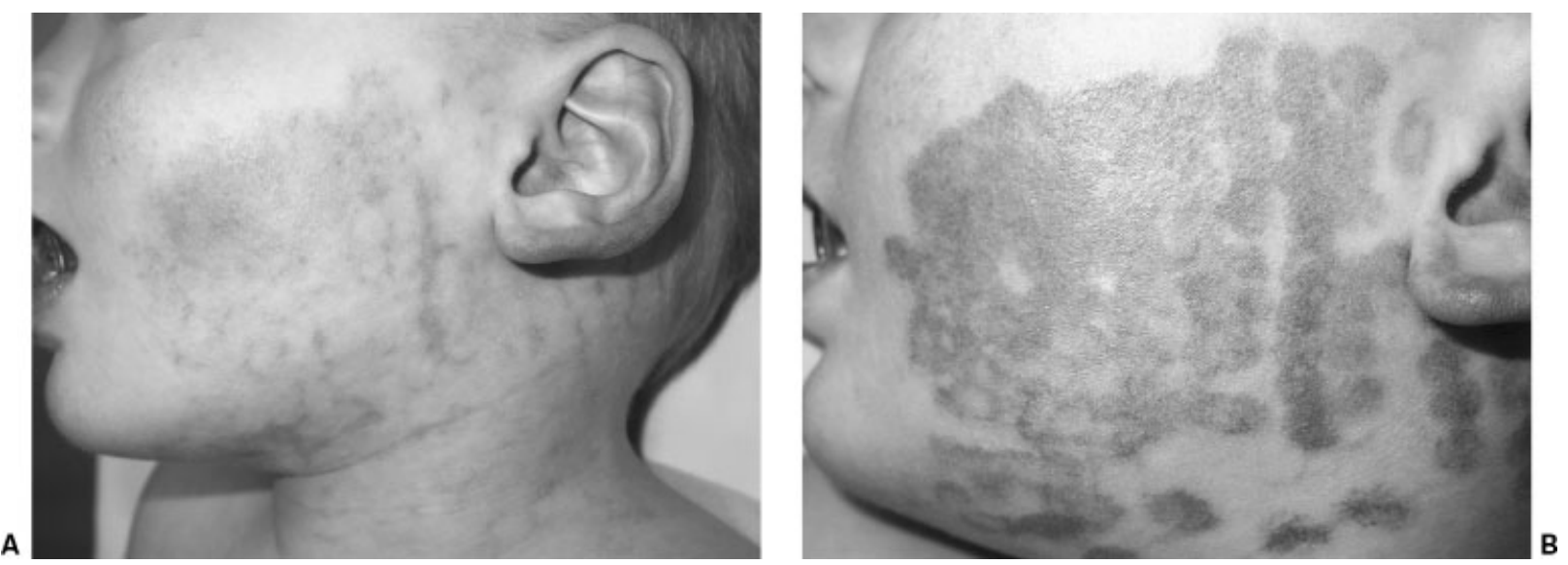

Figure 2 (A) Photograph of a child after one treatment with PDL. (B) Posttreatment photograph (PDL, 595 nm, 0.45 millisecond) illustrating darker purpura compared with that seen after the 1.5-millisecond treatment in Fig. 1B. 
wavelength a poor choice for darker skin types and increasing the risk of dyspigmentation. ${ }^{20,21}$

\section{Long-Pulsed Lasers}

Based on the deep penetration of long-wavelength light and a peak of hemoglobin absorption within the 800- to 900-nm range, long-pulsed millisecond domain alexandrite, diode, and neodymium:yttrium-aluminum-garnet (Nd:YAG) lasers have been developed to treat moderately deep, large-caliber vascular lesions. ${ }^{22-24}$ Characteristics of the available alexandrite lasers include wavelength of $755 \mathrm{~nm}$ and a pulse duration of 3 to 20 milliseconds; characteristics of the diode lasers are wavelengths of 800,810 , and $930 \mathrm{~nm}$ and a pulse duration of 10 to 250 milliseconds. ${ }^{22,25}$ Characteristics of the Nd:YAG lasers are wavelength of $1064 \mathrm{~nm}$ and pulse duration up to 100 milliseconds. Whereas results indicate that small vessels less than $0.4 \mathrm{~mm}$ in diameter are resistant to such long pulse durations, larger-caliber vessels respond relatively well to a series of treatments. ${ }^{24-26}$ The high fluence and long pulse duration of these lasers make them effective but also increase risk of complications. Epidermal cooling is vital with these machines, and overlapping or pulse stacking should be avoided to prevent blisters, scars, or ulceration. ${ }^{22-24}$

\section{Intense Pulsed Light Source}

High-intensity pulsed light sources emit single, double, or triple pulses of broadband light from $515 \mathrm{~nm}$ to 1200 $\mathrm{nm}$ in pulses 2 to 20 milliseconds in duration. ${ }^{27-29}$ Because both oxygenated and deoxygenated hemoglobin absorbs at these wavelengths, longer wavelengths penetrate deeper into skin, increasing the likelihood of damage to deep vessels. The intense pulsed light source is moderately effective in the treatment of PWS and evolving superficial hemangiomas, but its greatest strength may be in the treatment of lesions containing vessels $<0.2 \mathrm{~mm}$ in diameter. ${ }^{28,29}$ Adverse sequelae include occasional epidermal crusting, hyperpigmentation, and hypopigmentation. Although results of the treatment of vascular lesions, including leg veins, with the intense pulsed light source (Photoderm VL; Sharplan Inc., Needham, MA) can be encouraging, the technique requires significant experience to achieve good results. Unlike pulsed lasers where only the spot size and fluence can be varied, the intense pulsed light source offers a wide array of choices, including wavelength, fluence, number of pulses, and pulse delay time, and, as a result, ideal treatment parameters have been slow to be established. ${ }^{27-29}$

\section{PEDIATRIC VASCULAR LESIONS}

Based on underlying etiology, pediatric vascular defects may be classified as either malformations or vascular neoplasms. Vascular malformations may be further categorized as capillary, venous, arterial, lymphatic, or a mixture of those components. ${ }^{30-32}$

\section{Hemangioma}

Hemangiomas, vascular endothelial cell neoplasms, are often characterized by early, rapid proliferation and eventual regression. Present in up to 3\% of newborns, hemangiomas initially appear as telangiectatic macules or blanched spots. ${ }^{30,31}$ Lesions commonly present around 2 weeks after birth, and up to $90 \%$ are recognized within the first month of life. Although the incidence of such tumors is increased in females, premature infants appear particularly prone to hemangioma development as well. ${ }^{30-32}$ Although a majority of hemangiomas begin to slowly involute by 1 year of age, complete resolution often takes 5 to 12 years. Regression typically occurs in $50 \%$ of patients by age 5 , in $70 \%$ by age 7 , and in $90 \%$ by age $9 .^{30-32}$ Because a majority of hemangiomas spontaneously involute, management is generally conservative with regular follow-up and frequent parental reassurance. However, many lesions are defined by a less predictable course, such as nasal tip or eyelid location, ulceration, sites associated with significant dysfunction, or lack of treatment response. ${ }^{30-32}$ Although corticosteroids are often first-line therapy, laser treatment can be useful as an adjuvant or as an alternative in certain situations. Indications for laser therapy include airway distortion, the threat of ocular occlusion, and ulceration frequently associated with the proliferative phase, as well as residual telangiectasia. Psychological distress may also prompt laser application. ${ }^{30-32}$

The selection of optimal laser therapy for hemangiomas depends strongly on the evolutionary stage of the lesion. ${ }^{30-33}$ Early lesions or those late in the evolutionary phase tend to respond better to such treatment. General considerations also include distribution pattern. Localized lesions typically have an improved prognosis compared with segmental or diffuse lesions associated with structural anomalies. ${ }^{32}$ Frequently resulting in significant clearing after two or more laser sessions, therapy is most effective in telangiectatic-type hemangioma. ${ }^{34-36}$

In an effort to diminish growth, some clinicians suggest early treatment of the macular precursor lesion. Treatment parameters of pulsed dye lasers are generally $595 \mathrm{~nm}, 1.5$ milliseconds, 6 to $7 \mathrm{~J} / \mathrm{cm}^{2}$ with epidermal cooling. ${ }^{31,32}$ Fluences will vary with skin type and other considerations such as response to prior management. Geronemus et $\mathrm{al}^{6}$ demonstrated a lack of effect on deeper lesion components; however, these lesions are rarely seen early enough and have typically entered the proliferative phase by the time of presentation. Between 3 and 9 months, hemangiomas may show ulceration, bleeding, and infection during the active proliferation phase. ${ }^{30-32}$ Pulsed dye laser therapy is frequently successful at 
treating ulcerations within both proliferative and involuting phases. Sufficient to induce vessel closure yet avoid additional ulceration, treatment parameters are generally set at low fluence $(595 \mathrm{~nm}, 1.5$ milliseconds, 6 to $7 \mathrm{~J} / \mathrm{cm}^{2}$ with epidermal cooling). ${ }^{31,32}$

\section{Postregression Telangiectasia}

Laser therapy is remarkably effective in the management of superficial, postregression telangiectases. While a majority of hemangiomas regress almost totally, residual markings may manifest in the form of facial telangiectasia, fibrofatty masses, or epidermal atrophy. ${ }^{23,33}$ For management of residual telangiectasia after hemangioma involution, PDL is the treatment of choice. Minimal effect, if any, on the underlying fibrofatty residue is achieved. With an incidence of less than $1 \%$, potential side effects of PDL treatment include ulceration with scarring and hypopigmentation that becomes more evident with further regression. ${ }^{25,33}$ Whereas PDL may effectively manage residual telangiectasia, use of the erbium:YAG (Er:YAG) laser may be considered an additional option to achieve improved cosmesis, especially if textural change is a major concern. Therapy should be considered at any age, though ideal management of postregression telangiectasia may occur from 5 to 10 years of age before scarring becomes more resistant. ${ }^{24-26,33}$

\section{Capillary Malformation (Port Wine Stain)}

Capillary malformations $(\mathrm{CMs})$ are composed of ectatic dermal vessels. Typically present at birth, these low-flow lesions occur with a prevalence of 0.3 to $0.5 \% .{ }^{13-15} \mathrm{In}$ contrast with "salmon patches" or macular stains, $\mathrm{CMs}$ never resolve spontaneously but may darken and become increasingly nodular with age. ${ }^{13-15}$ Histologically, normal epidermal structures overlie an abnormal dermal plexus of dilated capillaries with depths from 100 to $1000 \mu \mathrm{m}$. Capillary malformations are frequently complex, and three patterns of vascular ectasia have been recognized: ectasia of the vertical loops of the papillary plexus; ectasia of the deep horizontal vessels in the papillary plexus; and a combination of vertical and horizontal vascular ectasia. ${ }^{15-17}$ After PDL treatment, $\sim 65 \%$ of patients achieve between $50 \%$ and $90 \%$ lightening and $15 \%$ achieve greater than $90 \%$ lightening of their lesions (Fig. 3). With individual treatment sessions spaced $\sim 2$ to 3 months apart, 8 to 10 serial treatments are often needed to achieve significant lightening of lesions. ${ }^{13,15-17}$

General anesthesia is deemed safe and facilitates significantly less traumatic treatment of infants and small children. Specific to PDL use, precautions such as a wrap-around wet gauze should be utilized to avoid endotracheal tube damage as well as flash fires resulting from oxygen ignition. For treating resistant PWS, longer PDL wavelengths (up to $600 \mathrm{~nm}$ ) and high fluences $\left(15\right.$ to $20 \mathrm{~J} / \mathrm{cm}^{2}$ ) delivered with cryogen cooling in two or three passes at least 30 seconds apart has proved effective. ${ }^{15,16}$ Particularly resistant PWS typically requires treatment with deeper penetrating, near-infrared lasers. Nd:YAG $(1064 \mathrm{~nm})$ or alexandrite $(755 \mathrm{~nm})$ lasers delivered at high fluences of 50 to $250 \mathrm{~J} / \mathrm{cm}^{2}$ in conjunction with proper skin cooling are particularly useful for deep, hypertrophic, or PDL-resistant lesions. ${ }^{22}$ Additionally, expanding target venules by increasing central venous pressure via patient crying or providing positive end-expiratory pressure during general anesthesia further facilitates laser effect. ${ }^{13,15,22}$
A

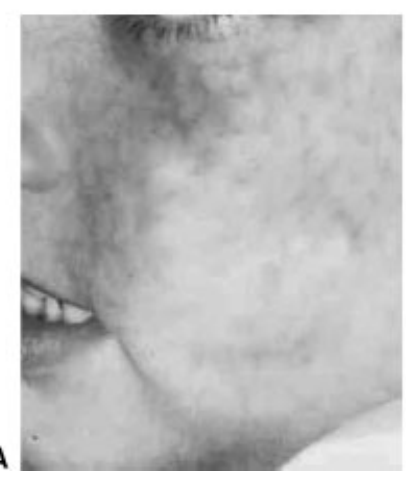

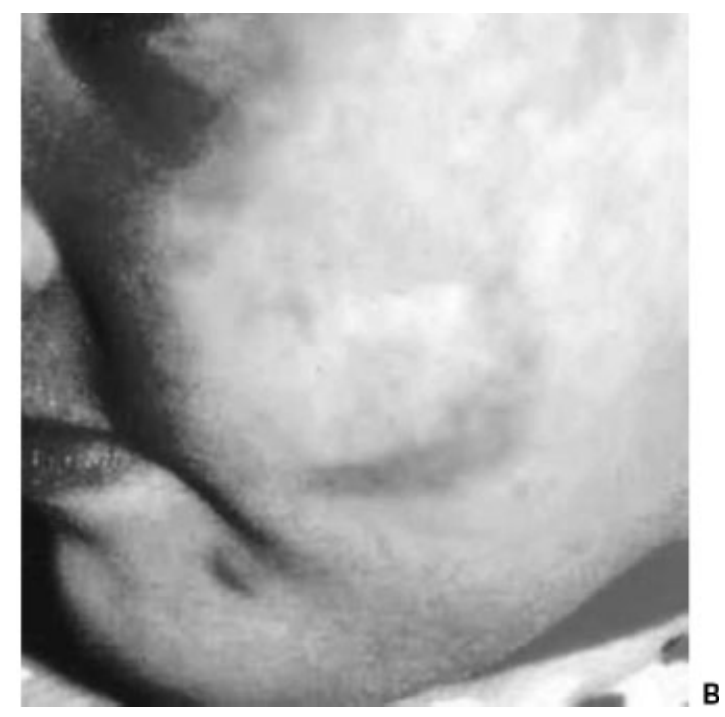

Figure 3 (A) Pretreatment photograph of a child with a facial CM. (B) Posttreatment photograph after four treatments (PDL, $585 \mathrm{~nm}, 0.45$ millisecond). 


\section{Venous Malformation}

Venous malformations (VMs) are congenital slow-flow lesions characterized by localized or diffuse ectasia of venous vasculature and frequently appear as combined venous-lymphatic malformations. ${ }^{34-36}$ Upon clinical examination, these lesions have a doughy, bluish appearance and expand with increased venous (orthostatic) pressure. The presence of phleboliths is pathognomonic. ${ }^{34-36}$ Although PDL therapy may be useful for superficial components of such lesions, more extensive VMs may be debulked via sclerotherapy, Nd:YAG, or KTP laser treatment followed by eventual surgical excision. ${ }^{35-37}$ Because VMs have a tendency for recanalization and recurrence, multiple laser treatment sessions are often necessary. ${ }^{34,37-40}$

\section{Lymphatic Malformation}

Lymphatic malformations consist of dilated lymphatic channels of varying diameters. ${ }^{41-43}$ Lined with lymphatic endothelium, lymphatic malformations may be categorized as microcystic, macrocystic, or combined. Clinically, superficial lymphatic malformations appear as translucent vesicles or blue-black and deep-red blebs. ${ }^{41-43}$ The most common indications for therapy include discomfort, fluid leakage, recurrent infections, and cosmetic concern. ${ }^{41-43}$

Several therapeutic modalities have been utilized in the treatment of lymphatic malformations; however, the PDL is enjoying significant recent success. Although carbon dioxide laser treatments can also be used effectively to create superficial fibrosis, mixed lymphatic venous malformations may better respond to a combination of $\mathrm{CO}_{2} / \mathrm{PDL} / \mathrm{Nd}$ :YAG laser. ${ }^{42,43}$ By stimulating lymphatic closure via endothelial damage, the goal of laser treatment is to limit symptoms. ${ }^{41-43}$ Because PDL, $\mathrm{CO}_{2}$, and Er:YAG therapy affects only more superficial portions of the lesions, deeper aspects of such malformations frequently go untreated. ${ }^{42,43}$ Nevertheless, symptoms such as lymphorrhea or bleeding may be substantially reduced after laser vaporization although lesions often recur. Although a majority of lymphatic malformations respond well to supportive or symptomatic management, acute bacterial infection should receive prompt antibiotic treatment, and more problematic lesions may require sclerotherapy or resection. ${ }^{41-43}$

\section{Telangiectasia}

Telangiectases are prominent superficial capillaries that may occur at any site. Although a majority of telangiectases are isolated, lesions may be a heralding sign of underlying disorders, such as Rothmund-Thomson syndrome, essential telangiectasia, Rendu-Osler-Weber syndrome, or hereditary hemorrhagic telangiectasia.
Most superficial telangiectases respond extremely well to PDL; typically only one to two treatments results in full resolution. ${ }^{24,25,33}$ Recent technical advances have allowed for effective therapy at subpurpuric settings, resulting in less postprocedure discoloration and discomfort. Although the KTP, Nd:YAG, diode systems, and intense pulsed light systems are effective, PDLs are the instrument of choice for superficial lesion components. ${ }^{25,33}$

\section{CLINICAL APPLICATION OF LASER THERAPY}

A majority of children may successfully complete officebased laser therapy via use of simple, topical anesthetics. Topical anesthesia is typically achieved with LMX, Ferndale Laboratories Inc., Ferndale, MN (4 or 5\% lidocaine), Ametop, Smith \& Nephew Healthcare, Astra, Kings Langley, UK (3\% amethocaine gel) or EMLA, AstraZeneca LP, Wilmington, DE (2.5\% lidocaine and $2.5 \%$ prilocaine) cream application 30 to 90 minutes prior to laser use. Because Ametop produces vasodilation, its use may increase local blood flow, improve intravascular energy absorption, and augment intralesional vascular destruction. In addition, cryogenic cooling spray or an air-cooling unit can effectively cool the epidermis to reduce local discomfort and minimize epidermal injury. ${ }^{5,7,11}$ Whereas older children can often tolerate laser therapy with topical anesthesia, very young patients or those with extensive lesions may require general anesthesia. In the event general anesthesia is required, one must keep in mind that the laser is a potential ignition source in the setting of highly volatile gas. ${ }^{9,11,14}$

\section{Laser Application}

Prior to formal laser therapy, particularly in patients with darker skin types, a test patch should be considered. Such patients are seen in 2 to 3 months to be evaluated for response to therapy. During each application, overlapping of pulses (25 to 30\%) is done with PDL. Immediate purpura, at least transiently, at treated sites is desired with PDL and indicates appropriate laser energy settings. ${ }^{11,15-17}$ In contrast, white or gray blistering of the tissue is indicative of excessive laser energy or reflection to surface.

\section{Postprocedure Care}

After treatment, most patients experience local ecchymoses, swelling, and discomfort consistent with a moderate-intensity sunburn. Ice packs, nonsteroidal antiinflammatory medications, and cooling gel application may minimize discomfort; however, local erythema or purpura may persist for 7 to 10 days. Less commonly, 
hyperpigmentation or hypopigmentation and atrophic scarring may be observed. Though rare, it is important to be aware of postprocedure infection. Topical antibiotic therapy may be initiated if crusting or scabbing raises concern of secondary bacterial infection. To further minimize postprocedure hypopigmentation, patients must be instructed to continue use of proper sunprotective agents. Emollients are also routinely applied until clearing of the purpura. Based on the vascular lesion treated, laser therapy is typically repeated at 8- to 12 - week intervals, and several treatments (3 to 15) are frequently required.

\section{FUTURE DIRECTIONS IN LASER THERAPY}

Laser therapy has revolutionized the treatment of pediatric vascular lesions. However, an accurate means to determine target vessel size and location does not currently exist, and laser settings are currently selected on the basis of available clinical information. In current use, photothermal imaging, ${ }^{44,45}$ optical Doppler tomography, ${ }^{46}$ and reflectance spectroscopy ${ }^{47}$ may help characterize epidermal thickness, melanin content, blood vessel depth, size, flow, and distribution. Though no standard preprocedure study accurately characterizes all pertinent parameters of target lesions, several imaging modalities continue to progress. In development, videomicroscopy, ${ }^{48}$ modulated imaging, ${ }^{49}$ cross-polarizing diffuse reflectance imaging, ${ }^{50}$ and laser speckle imaging ${ }^{51}$ are expected to have widespread clinical effect on vascular lesions in coming years. As an additional barrier to current therapy, vessels smaller than 30 to $50 \mu \mathrm{m}$ seem resistant to currently available options. Factors such as deep dermal vessel location, presence of shielding cluster vessels, or inadequate energy deposition due to too little intravascular mass continue to limit effective therapy. Advances in intralesional energy release or future applications that enhance deep penetration yet limit collateral damage may one day provide answers to current clinical dilemmas.

\section{CONCLUSION}

Since its introduction in 1967, the increasingly frequent exchange of surgical steel for laser therapy has benefited patients and physicians alike. After the first clinical application by Goldman, ${ }^{1-3}$ laser therapy has become indispensable in the management of vascular birthmarks. In selecting a proper balance of wavelength, pulse duration, and energy density (fluence), the physician can mold laser energy to effectively manage lesions once considered untreatable. Now the management modality of choice, the vast array of lesions amenable to laser therapy continues to expand. By advancing our understanding of both laser tech- nology as well as vascular lesion biology, the goal of providing optimal clearance with minimal morbidity moves ever closer.

\section{REFERENCES}

1. Anderson RR, Parrish JA. Selective photothermolysis: precise microsurgery by selective absorption of pulsed radiation. Science 1983;220:524-527

2. Arndt KA. Argon laser therapy of small cutaneous vascular lesions. Arch Dermatol 1982;118:220-224

3. Dixon JA, Huether S, Rotering RH. Hypertrophic scarring in argon laser treatment of portwine stains. Plast Reconstr Surg 1984;73:771-780

4. Chang CJ, Nelson JS. Cryogen spray cooling and higher fluence pulsed dye laser treatment improve port-wine stain clearance while minimizing epidermal damage. Dermatol Surg 1999;25:767-772

5. Apfelberg DB, Maser MR, Lash H, Rivers J. The argon laser for cutaneous lesions. JAMA 1981;245:2073-2075

6. Geronemus RG. Argon laser for the treatment of cutaneous lesions. Clin Dermatol 1995;13:55-58

7. No D, Dierick C, McClaren M, et al. Pulsed alexandrite treatment of bulky vascular malformations. Lasers Surg Med 2003;15:26

8. Apfelberg DB. Argon-pumped tunable dye laser. Ann Plast Surg 1994;32:394-400

9. Rohrer TE, Chatrath V, Iyengar V. Does pulse stacking improve results with variable-pulse pulsed dye lasers? Dermatol Surg 2004;30:163-167

10. Anderson RR, Ross EV. Laser-tissue interactions. In: Fitzpatrick MP, Goldman MP, eds. Cosmetic Laser Surgery. St. Louis, MO: Mosby; 2000:109-115

11. Levine VJ, Geronemus RG. Adverse effects associated with the 577- and 585-nanometer pulsed dye laser in the treatment of cutaneous vascular lesions: a study of 500 patients. J Am Acad Dermatol 1995;32:613-617

12. Garden JM, Polla LL, Tan OT. The treatment of port-wine stains by the pulsed dye laser. Analysis of pulse duration and long-term therapy. Arch Dermatol 1998;124:889-896

13. Tan OT, Sherwood K, Gilchrest BA. Treatment of children with portwine stains using the flashlamp-pumped pulsed dye laser. N Engl J Med 1989;320:416-421

14. Fitzpatrick RE, Lowe NJ, Goldman MP, et al. Flashlamppumped pulsed dye laser treatment of port-wine stains. J Dermatol Surg Oncol 1994;20:743-748

15. Sommer S, Sheehan-Dave RA. Pulsed dye laser treatment of port-wine stains in pigmented skin. J Am Acad Dermatol 2000;42:667-671

16. Waldorf HA, Alster TS, McMillan K, et al. Effect of dynamic cooling on 585-nm pulsed dye laser treatment of port-wine stain birthmarks. Dermatol Surg 1997;23:657-662

17. Renfro L, Geronemus RG. Anatomical differences of portwine stains in response to treatment with the pulsed dye laser. Arch Dermatol 1993;129:182-188

18. Lou WW, Geronemus RG. Treatment of port-wine stains by variable pulsed width pulsed dye laser with cryogen spray: a preliminary study. Dermatol Surg 2001;27:963-965

19. Dierickx CC, Casparian JM, Vengopalan V, Farinelli WA, Anderson RR. Thermal relaxation of port-wine stain vessels probed in vivo: the need for 1-10 millisecond laser pulse treatment. J Invest Dermatol 1995;105:709-714 
20. Uebelhoer NS, Bogle MA, Dover JS, Rohrer TE, Arndt KA. Comparison of KTP (532nm Gemini) with pulsed dye laser $(595 \mathrm{~nm}, \mathrm{~V}$-Beam) in the treatment of facial telangiectasia and redness. Unpublished data

21. Butler EG, McClellan SD, Ross EV. Split face treatment of photodamaged skin with a $10 \mathrm{~mm}$ spot KTP laser vs IPL: a cheek-to-cheek comparison. Lasers Surg Med 2006;38: 124-128

22. Yang MU, Yaroslavsky AN, Farinelli WA, et al. Long pulsed $\mathrm{Nd}$ :YAG treatment for port wine stains. Am Acad Dermatol 2005;52:480-490

23. Parlette EC, Groff WF, Kinshella MJ, Domankevitz Y, Ross EV. Optimal pulse durations for the treatment of leg telangiectasias with a neodymium YAG laser. Lasers Surg Med 2006;17:342-347

24. Iyer S, Fitzpatrick RE. Long-pulsed dye laser treatment for facial telangiectasias and erythema: evaluation of a single purpuric pass versus multiple subpurpuric passes. Dermatol Surg 2005;31:898-902

25. Lupton JR, Alster TS, Romero P. Clinical comparison of sclerotherapy versus long-pulsed Nd:YAG laser treatment for lower extremity telangiectases. Dermatol Surg 2002;28:694697

26. Goldberg DJ, Meine JG. A comparison of four frequencydoubled Nd:YAG (532 nm) laser systems for treatment of facial telangiectasias. Dermatol Surg 1999;25:463-467

27. Negishi K, Kushikata N, Tezuka Y, et al. Study of the incidence and nature of very subtle epidermal melasmaQ in relation to intense pulsed light treatment. Dermatol Surg 2004;30:881-886

28. Negishi K, Tezuka Y, Kushikata N, Wakamatsu S. Photorejuvenation for Asian skin by intense pulsed light. Dermatol Surg 2001;27:627-632

29. Dover JS, Bhatia AC, Stewart B, Arndt KA. Adjunctive use of topical aminolevulinic acid with intense pulsed light in the treatment of photoaging. Arch Dermatol 2005;141:12471252

30. Burton BK, Schulz CJ, Angle B, Burd LI. An increased incidence of hemangiomas in infants born following chorionic villus sampling (CVS). Prenat Diagn 1995;15:209-214

31. David LR, Malek MM, Argenta LC. Efficacy of pulse dye laser therapy for the treatment of ulcerated hemangiomas: a review of 78 patients. Br J Plast Surg 2003;56:317-327

32. Sadick NS. A dual wavelength approach for laser/intense pulsed light source treatment of lower extremity veins. J Am Acad Dermatol 2002;46:66-72

33. Kaudewitz P, Klovekorn W, Rother W. Effective treatment of leg vein telangiectasia with a new $940 \mathrm{~nm}$ diode laser. Dermatol Surg 2001;27:101-106

34. Dover JS, Sadick NS, Goldman MP. The role of lasers and light sources in the treatment of leg veins. Dermatol Surg 1999;25:328-336

35. Kauvar ANB. The role of lasers in the treatment of leg veins. Semin Cutan Med Surg 2000;19:245-252
36. Sadick NS. Long-term results with a multiple synchronizedpulse $1064 \mathrm{~nm} \mathrm{Nd:YAG} \mathrm{laser} \mathrm{for} \mathrm{the} \mathrm{treatment} \mathrm{of} \mathrm{leg}$ venulectasias and reticular veins. Dermatol Surg 2001;27: 365-369

37. Goldman MP. Laser and sclerotherapy treatment of leg veins: my perspective on treatment outcomes. Dermatol Surg 2002;28:969-970

38. Massey RA, Katz BE. Successful treatment of spider leg veins with a high-energy, long-pulse, frequency-doubled neodymium:YAG laser (HELP-G). Dermatol Surg 1999;25:677680

39. Passeron T, Olivier V, Duteil L, et al. The new 940nanometer diode laser: an effective treatment for leg venulectasia. J Am Acad Dermatol 2003;48:768-774

40. Bernstein EF. Clinical characteristics of 500 consecutive patients presenting for laser removal of lower extremity spider veins. Dermatol Surg 2001;27:31-33

41. Lai CH, Hanson SG, Mallory SB. Lymphangioma circumscriptum treated with pulsed dye laser. Pediatr Dermatol 2001;18:509-510

42. Weingold DH, White PF, Burton CS. Treatment of lymphangioma circumscriptum with tunable dye laser. Cutis 1990;45:365-366

43. Bekhor P. Lasers in Dermatology. Aust Fam Physician 1992;21:577-580

44. Telenkov SA, Dave DP, Sethuraman S, Akkin T, Milner TE. Differential phase optical coherence probe for depthresolved detection of photothermal response in tissue. Phys Med Biol 2004;49:111-119

45. Choi B, Majaron B, Nelson JS. Computational model to evaluate port wine stain depth profiling using pulsed photothermal radiometry. J Biomed Opt 2004;9:299-307

46. Sivarajan V, Mackay IR. Noninvasive in vivo assessment of vessel characteristics in capillary vascular malformations exposed to five pulsed dye laser treatments. Plast Reconstr Surg 2005;115:1245-1252

47. Zhang R, Verkruysse W, Choi B, et al. Determination of human skin optical properties from spectrophotometric measurements based on optimization by genetic algorithms. J Biomed Opt 2005;10:024030

48. Eubanks LE, McBurney EI. Videomicroscopy of port-wine stains: correlation of location and depth of lesion. J Am Acad Dermatol 2001;44:948-951

49. Cuccia DJ, Bevilacqua F, Durkin AJ, Tromberg BJ. Modulated imaging: quantitative analysis and tomography of turbid media in the spatial-frequency domain. Opt Lett 2005;30:1354-1356

50. Jung B, Choi B, Durkin AJ, Kelly KM, Nelson JS. Characterization of port wine stain skin erythema and melanin content using cross-polarized diffuse reflectance imaging. Lasers Surg Med 2004;34:174-181

51. Choi B, Ramirez-San-Juan JC, Lotfi J, Stuart Nelson J. Linear response range characterization and in vivo application of laser speckle imaging of blood flow dynamics. J Biomed Opt 2006;11:041129 